\title{
Palavras livres, pesadas, suculentas: Das três riches heures aos livros de artista
} Free, succulent, heavy words: From the Três riches heures to the artist's books

Telma Scherer ${ }^{1}$ 


\section{Resumo}

O artigo propõe uma reflexão sobre o livro, abordando sua dimensão espaço-temporal e as relações entre palavra e imagem. Partindo do livro de horas medieval, reflito sobre o significado do livro e seu alcance na época para, em seguida, dedicar-me às proposições do século XX que repensam sua estrutura e sentidos múltiplos. Evoco as reflexões de Ulises Carrión sobre a arte de fazer livros, bem como uma breve genealogia da Poesia Concreta. A prática medieval traz uma dimensão ritual que pode ser comparada à feitura dos livros de artista. Para finalizar a abordagem sobre a relação entre palavra e imagem, trago um trabalho de Dario Robleto que parte da grafia como vazio preenchido, redimensionando as tensões entre palavra e obra de arte. Pode-se constatar que tanto poetas quanto artistas visuais ousaram e ousam atravessamentos no espaço da página, gerando interessantes tensões entre grafia e signo, imagem e significado.

Palavras-chave: livro de artista, livro de horas, poesia

\section{Abstract}

The paper proposes a reflection on the book by addressing its space-time dimension and the relations between words and images. Based on the medieval book of hours, I reflect on the meaning and scope of the book in that times to then analyse the propositions of the twentieth century in order to rethink its structure and multiple meanings. I evoke Ulises Carrión's reflections on the art of making books, as well as a brief genealogy of Concrete Poetry. The medieval practice brings a ritual dimension that can be compared to the making of artist books. To complete the discussion on the limits between word and image, I bring a work of Dario Robleto that brings writing as an empty space, resizing tensions between words and works of art. Poets and visual artists so dared and dare crossings within the page, creating interesting tensions between spelling and sign, images and meaning.

Keywords: artist book, book of hours, poetry

ISSN: 1808-3129

\footnotetext{
1 Telma Scherer

Doutoranda em Teoria Literária - UFSC, Brasil

Graduanda em Artes Visuais - UDESC, Brasil

telmascherer@gmail.com
} 


\section{As malhas da estrutura: livros pensados e pesados}

A ideia geral deste artigo tomou proveito da leitura dos primeiros capítulos da dissertação de Márcia Regina Pereira de Sousa, publicada em 2011, O livro de artista como lugar tátil. Apresentando um panorama das "(In)definições acerca do livro de artista", a autora inicia seu percurso citando o texto-fundamento de Ulises Carrión, "The new art of making books". Senti-me impelida à leitura desse manifesto apresentado pelo autor em 1975 que é, ao mesmo tempo, um exemplo condensado de teoria literária, filosofia e clara apresentação de uma poética que influenciou as gerações seguintes. Ulises Carrión iniciou sua trajetória como escritor para, posteriormente, romper com a literatura em seu sentido tradicional e dedicar-se ao campo das artes visuais. Sem deixar de nutrir a paixão pelos livros, propôs, em suas obras, novas possibilidades para esses objetos, tendo sido o fundador da primeira livraria dedicada especialmente aos livros de artista, a "Other books and so", em Amsterdam. Nesta introdução, mais do que apresentar as ideias expostas por Sousa ou Carrión, pretendo traçar uma genealogia do contexto no qual surge o livro de artista a partir da poesia moderna. Em seguida, após essa breve fundamentação, passarei a abordar as iluminuras medievais, lidas em clave contemporânea.

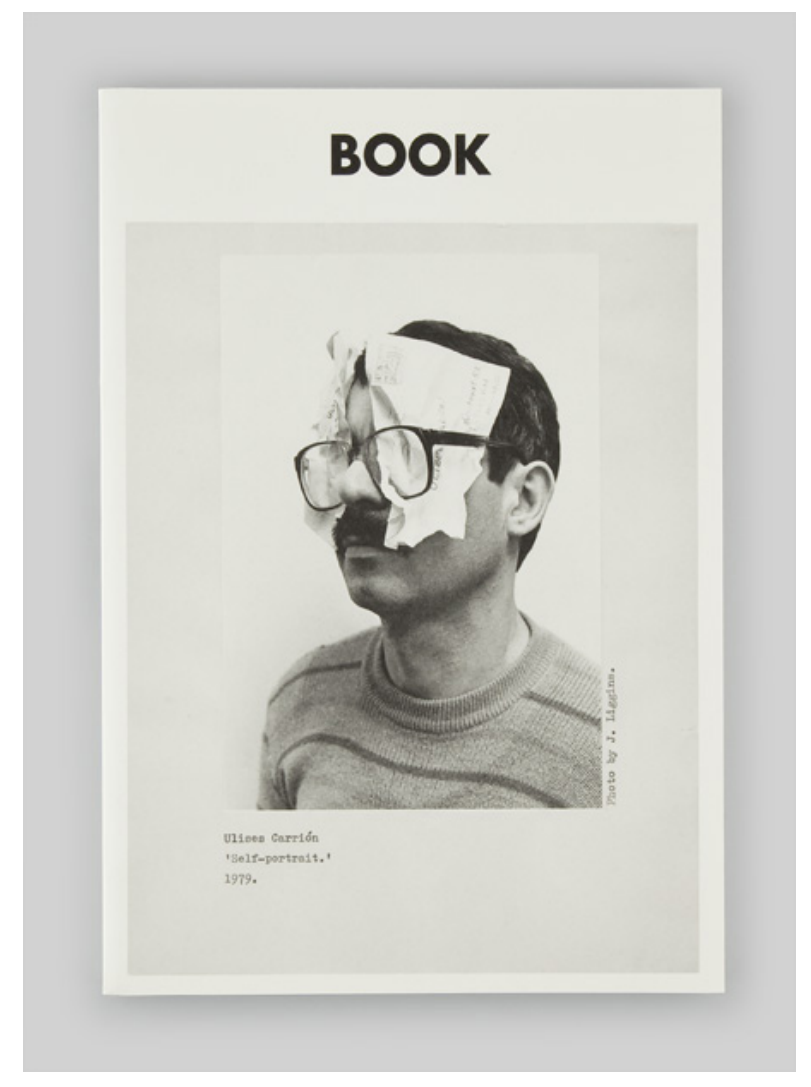

Capa do livro Book, dedicado à obra de Ulises Carrión, contendo um trabalho do artista, de 1979. Fonte da imagem: http://eastsideprojectsorg/publications/book, 30.04.1979 
open tuesday to saturday

$10 \mathrm{am}-1 \mathrm{pm}, 2 \mathrm{pm}-5.30 \mathrm{pm}$

$\mathrm{B}^{00 K_{S}}$

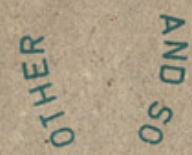

amsterdam

181.256781

amrobank 43.30.47.046

postgiro $\mathrm{nr} 3366599$

t.n.v. u. carrión-bogard a space for

exhibition and

distribution

other books

non books

anti books

pseudo books quasi books

concrete books visual books

conceptual books

structurai books

project books

statements books

instruction books

and

musical scores

postcards

posters

objects

sound poetry

Fonte da imagem: https://mailartists. files.wordpress.com/2011/01/carric3b3n.jpg, 30.04.1979.

Desde o século XIX, os poetas vinham questionando o formato do livro, o desleixo dos escritores pela sua estrutura; investigando novas composições formais, como Mallarmé no célebre poema "Um lance de dados jamais abolirá o acaso". Por outro lado, criadores como El Lissitsky, ligado ao construtivismo russo, apresentou obras como História de Dois Quadrados, que já experimentavam o livro de forma artística. Influenciados por toda essa tradição, os poetas concretistas, em meados do século $X X$, propuseram novos rumos para a poesia. Apenas nos anos 70, entretanto, quando o livro de artista tornou-se uma prática mais prolífica, foi possível ler uma reflexão metapoética sistematizada, como a de Ulises Carrión. Há, portanto, que acompanhar a linha de um desenvolvimento experimental e investigativo, começando na afirmação mallarmaica de que tudo existe para culminar num livro.

Ainda no século XIX, Mallarmé (1842-1898) reflete sobre a materialidade do livro, comparando-o com a monotonia das colunas de jornal, estas segundo ele de uma padronização danosa. A leitura do livro requer do leitor uma ação, representada pelo ato de abrir a dobradura das páginas com o corta-papel - arma que funciona, também, ritualmente. Há uma ação na leitura, um movimento imprescindível do leitor, que aponta já para essa consciência do livro como espaço físico.

Teorizando acerca da estrutura do livro, Mallarmé aponta a letra como elemento básico: "O livro, expansão total da letra, deve dela tirar, diretamente, uma mobilidade e espaçoso, por correspondências, instituir um jogo, não se sabe, que confirme a ficção" (MALLARMÉ, 2010, p.180). Sua poética, elaborada em textos críticos, vem remeter diretamente a poemas como "Um lance de dados jamais abolirá o acaso", no qual o espaço da página, fontes, tabulações e seções em branco são particularmente explorados. Um pouco mais tarde, Guillaume Apollinaire (1880-1918) lançará seus Caligramas, produzidos entre 1914 a 1916, e lançados no ano da morte 
do autor. Apollinaire fará poemas visuais, dispondo as letras em formas que, subvertendo a linha reta da diagramação comum, apontarão para uma nova dimensão do significante.

No advento da poesia concreta, a lição de Mallarmé terá múltiplas ressonâncias, gerando outras leituras. As contribuições dos movimentos do início do século XX também irão reaparecer, em toda a sua vivacidade, no concretismo brasileiro, que se instalou como arte de vanguarda. O construtivismo russo foi o gerador de importantes referências para o campo desta poesia, que nunca deixou de professar seus intercâmbios com as artes visuais. O construtivismo influenciou as principais construções de ruptura que tiverm morada, tanto no Brasil quanto na Europa, na primeira metade e meados do século XX. Os poetas concretistas admiravam profundamente precursores como Maiakovski, e suas reflexões jamais teriam sido possíveis caso uma nova ordem para a arte não tivesse se instalado desde os primórdios do futurismo russo. A valorização da experimentação com os tipos e as ilustrações tanto para a escrita de poesia quanto para o design de cartazes teve amplo desenvolvimento nos inícios do século XX. A investigação da geometria e a construção de obras como as de El Lissistky demonstram a importância do movimento construtivista nessa tradição.

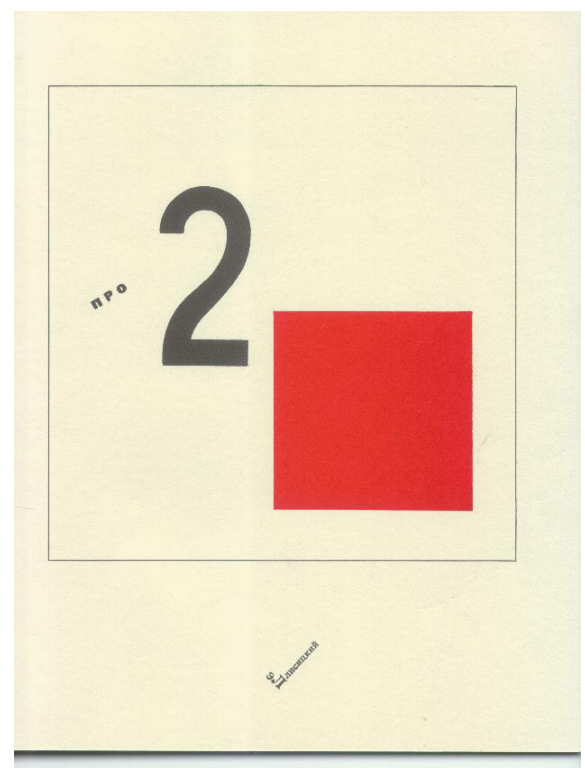

Capa de História de dois quadrados, El Lissitsky, 1922. Fonte da imagem: http://www.eldritchpress.org/el/pro.html, 30.04.2015

Em relação à literatura brasileira, um dado interessante é o fato de ser o concretismo a única seara na qual os nossos autores tiveram um destaque marcante no cenário internacional. Augusto e Haroldo de Campos, Décio Pignatari tiveram trânsito entre criadores como e. e. cummings, traduzido e publicado por Augusto de Campos no Brasil, entre outros diálogos com autores e músicos de vanguarda. Eles são citados no livro de Ulises Carrión, comprovando a influência que a Poesia Concreta brasileira operou sobre este. Esses criadores procuraram levar às últimas consequências as descobertas de Mallarmé e Apollinaire a respeito das flexibilidades no uso espacial do significante. Suas experiências procuraram exaurir as possibilidades da letra para, em alguns casos, superá-la na construção de poemas visuais e sonoros que ultrapassam o livro. 


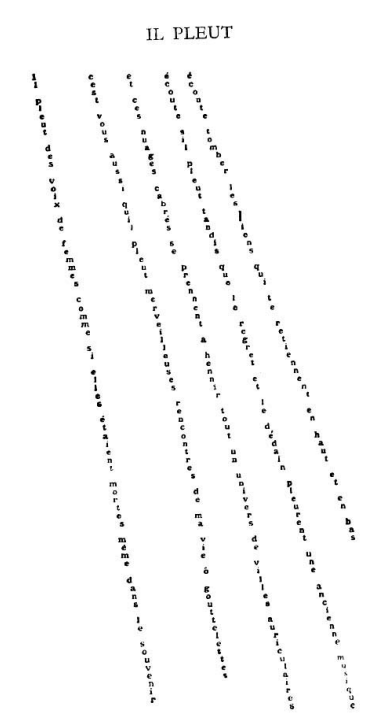

II pleut (Chove). Poema de Apollinaire. Fonte da imagem: http://expurgacao.art.br/wp-content/uploads/2014/03/cligramas\%E2\%80\%9DFigura-14-do-poeta-Guillaume-Apollinaire-1880.jpg, 30.04.2015.

A Poesia Concreta foi também um espaço de discussão, de manifestação teórica dos seus atores principais. Manifestos e livros críticos desvelaram as referências do movimento, a exemplo da Teoria da poesia concreta, volume que reúne artigos e depoimentos de processos e procedimentos de Décio Pignatari, Augusto e Haroldo de Campos.

Entre as principais contribuições nesse campo está a afirmação do verbivocovisual como espaço de feitura da poesia. Esta quebrou limites de suportes e modos de veiculação do texto, que passou a ser pensado como um significante complexo no qual som, imagem e significado contribuem igualmente, gerando as tensões estéticas características da fruição do poema. Os poetas concretos apropriaram-se das tecnologias de imagem e áudio disponíveis, criaram poemas sonoros e lançaram as bases para as criações que vieram a seguir, na esteira das novas possibilidades de recursos em vídeo e hipertexto.

A herança de Ezra Pound se torna notável nos concretos brasileiros, bem como a sua teoria de aplicação à poesia dos estudos de ideogramas chineses feito por Ernst Fenollosa. A utilização de ideogramas, desenhos que remetem diretamente à forma das coisas, encantou os ocidentais por revelar a materialidade do significante, sua presença coisal, seu peso enquanto forma.

Na tradição do Ocidente, temos a pergunta platônica do Crátilo: em que ponto o som significante e o significado se unem? É possível estabelecer uma conexão segura entre os dois? A resposta de Platão nesse diálogo é negativa, embora abundem os exemplos nos quais a sonoridade de certos fonemas leve ao significado das palavras. Se a língua tivesse uma origem totalmente onomatopaica, revelando a etimologia essa ligação inconteste entre significante e significado, então a escrita ocidental talvez fosse como o ideograma chinês, porém em interface sonora ao invés de visual.

No caso da antiga escrita chinesa, pode-se observar a complexidade da formação de imagens que coadunam significados, numa etimologia de leitura visual que 
surpreende pela adequação do traço à coisa. Pound afirma, maravilhado, que seu amigo desenhista conseguia ler os ideogramas sem qualquer conhecimento da língua chinesa, apenas pela interpretação das figurações contidas nos traços concisos. O poeta também exemplifica a formação do ideograma para "vermelho" que se dá pela síntese dos ideogramas de "flamingo", "ferrugem", "cereja" e "rosa". Uma noção que, não tendo direta representação pelo traço, é formada através do agrupamento de noções concretas.

Os estudos dos ideogramas possibilitaram a Pound teorizar uma forma de ler e escrever poesia que está interessada em priorizar a materialidade do significante, e por isso abriram espaço para as posteriores criações da poesia-práxis, poesia concreta e visual.

Interessa-me, para os fins desta introdução, revelar o caminho que a poesia moderna percorreu para que uma nova concepção da literatura chegasse ao ponto de se misturar com as artes visuais, gerando trânsitos que levaram o poeta Ulises Carrión, por exemplo, da escrita de poemas para as reflexões sobre o livro como objeto, e criações como os contemporâneos livros de artista.

\section{Lindos e livres: livros medievais e contemporâneos}

Comumente se entendia (e o senso comum ainda entende) o livro como meio veiculador de conteúdos literários, instrumento de transporte dos significados, cuja forma seria indiferente, não relacionada, à literatura em si. Escritores seriam aqueles que compõem a série de palavras a serem dispostas em formatos, fontes e papéis quaisquer, geralmente escolhidos por um profissional diferente e cuja função de autoria no livro não é reconhecida. O diagramador, ainda hoje, é um criador quase invisível, cujo nome não figura na capa e raras vezes é celebrado. Infelizmente, quando fazem menção ao aspecto visual do livro, as editoras destacam, quando muito, os ilustradores.

Em "A nova arte de fazer livros", Carrión faz uma abordagem desse aspecto, enfatizando que na velha arte de fazer livros o autor fazia apenas o texto, e na nova arte o autor faz o livro. Ele pensa o livro como um conjunto do qual o texto é apenas um elemento. Sua definição é a que segue: "To make a book is to actualize its ideal space-time sequence by means of the creation of a parallel sequence of signs, be it linguistic or other" (CARRIÓN, 2010, s/n). Carrión vai mais além da proposta mallarmaica do livro como expansão da letra; libera-o dela, confere-lhe liberdade em sua estrutura e forma para revelar, como essência, sua dimensão espaço-temporal, traduzida na sequência de páginas/espaços/instantes.

Se relacionarmos as iluminuras medievais à concepção de Carrión, os livros de horas estariam mais perto da nova arte. Seu conteúdo textual refere-se não tanto a uma criação de autor, mas a palavras a serem celebradas em determinadas horas, orações. Se tomarmos como exemplo o livro Très riches heures du Duc de Berry ${ }^{1}$,

\footnotetext{
1 O livro faz parte da biblioteca dos "Domaines de Chantilly", antigo patrimônio de príncipes franceses e hoje instituição que preserva um castelo de fins da Idade Média com o Museu Condé e Biblioteca, jardins e um Museu Vivo do Cavalo. As informações quanto ao livro foram retiradas do site http://www.chateaudechantilly.com.
} 
constatamos que a noção de sequencialidade é o principal fator a ser considerado. Mais do que o receptáculo de um texto a ser lido, esse livro é uma celebração da sequência do tempo. Contendo orações que deveriam ser repetidas em determinadas horas do dia, seguindo portanto a tradição dos breviários então popularizados fora do âmbito clerical, ele se constitui de uma sequência de espaços-tempos cuja função é ritual. Seu resultado é uma performance: o acontecimento real da oração a ser repetida por seu dono e familiares, provavelmente em voz alta e com a presença física do livro apenas a lhes indicar o rumo desse rito a ser repetido.

A palavra da oração distancia-se da significação comum. É uma palavra performativa, pois quem a profere não está interessado em comunicar algo a alguém, e sim em efetuar uma alteração no mundo. Como outras palavras performativas, ela realiza uma ação: o "sim" dos casamentos, as palavras mágicas da feitiçaria, o juramento diante do juiz... São usos da palavra que podem ser entendidos não como texto comunicativo, e sim como deslocamentos para a ação: são palavras que fazem coisas, ao invés de informá-las. É provável que muitos dos que compareciam ao momento das orações diárias não compreendessem o significado denotativo de cada uma das palavras entoadas, e nem por isso tinham menos fé suas orações: caso das crianças que, embora não dominem o sentido linguístico das preces, acredita-se terem um poder de comunicação com a santidade maior do que os adultos, na tradição católica. Este também é o caso das palavras mágicas, cujo significado não é conhecido.

Feita essa consideração sobre o caráter das palavras contidas no livro de horas, também cabe reiterar que é um livro ritual, cujo emprego se dá em uma ocasião litúrgica. As orações marcam a sequência dos dias em seus momentos pontuados de ritos a serem cumpridos, e suas iluminuras também apontam para a consagração dos símbolos que marcam essa passagem do tempo. Nesse sentido, as marcas visuais que apontam para a cronologia abundam nas páginas do livro do Duc de Berry, reiterando seu caráter espaço-temporal: são ilustrações para a passagem dos meses, símbolos astrológicos, mapas cronológicos das estações do ano, dos signos, dos momentos do dia. Na página conhecida como "Anatomical Man" vemos uma figura humana perpassada pelos signos do zodíaco e envolta em um halo que marca os dias do ano, os meses, os signos do zodíaco.

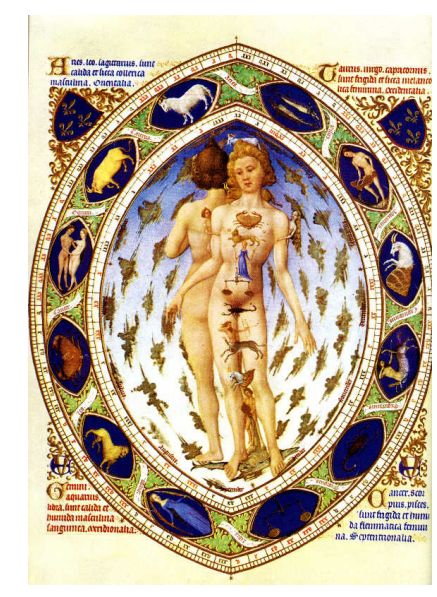

Fonte da imagem: http://www.christusrex.org/www2/berry/f14v.html, 03/07/2014. 
Esse homem medieval interessado na contagem do tempo, e assim adepto ao conceito de Carrión ("A book is a space-time sequence") também explora a espacialidade da página. Ainda não se conhecia o processo de fabricação em massa que padronizou os livros, através da impressão. O trabalho minucioso de feitura aponta o preciosismo da estética gótica, sendo as iluminuras desses pergaminhos exemplares do refinamento a que a pintura da época chegou.

Tal como muitos dos contemporâneos livros de artista, o livro medieval é um exemplar único, produzido artesanalmente. É interessante notar que a imprensa, ao mesmo tempo em que difundiu os livros, também os padronizou em uma forma que, poeticamente, teve de ser superada para um "retorno" à liberdade (o que Ulises Carrión chama a nova arte de fazer livros). A nova arte ironicamente reinaugura procedimentos comuns à Idade Média.

Esses velhos livros medievais, construídos com tanto esmero para fins religiosos, circulavam em um meio onde ter mais de um livro em casa era uma raridade. 0 Duc de Berry, que encomendou esse livro célebre, era um homem culto e extravagante. Conta-se que entre suas posses tinha diversas Bíblias e vários livros de horas, porém em número que não preencheria uma só das estantes de nossas bibliotecas contemporâneas. Tanto a escassez de livros que caracteriza a Idade Média quanto a superabundância do mercado editorial contemporâneo levam à mesma solução do livro de exemplar único cuja forma é produzida com esmero a partir de um conceito bem planejado.

No caso do livro Très riches heures, o conceito provinha dos breviários, porém a utilização da astrologia e a concepção das iluminuras marcando meses e estações foram bem pensadas. Houve intervenção de vários artistas. A intenção da feitura está na encomenda de um homem culto e exigente, que supervisionou a composição das primeiras iluminuras, feitas pelos irmãos Limbourg, Paul, Jean, Hernam. Sabe-se que em uma segunda fase colaborou Barthélemy d'Eyck, por volta de 1400. Finalmente, de 1485 a 1489, Jean Colombe trabalhou no livro.

Em mais de 80 anos, revezaram-se os iluminadores para criar o que hoje conhecemos - um exemplar tido como ainda inconcluso, que passou pela posse de várias famílias e o silêncio de três séculos até ser redescoberto no século XIX. Ele foi produzido entre 1412 e 1489 e reencontrado, através de uma compra do bibliófilo Duc de d'Aumale, em 1856. Passaram-se 30 anos para sua identificação dentro das posses do Duc de Berry. São 206 folhas com 65 ilustrações pequenas e 66 grandes. Chama a atenção a integração entre palavra e imagem, com números, caracteres góticos, símbolos, figuras humanas e paisagens formando um todo coerente e preciso. É um traço dessa feitura medieval a integração das imagens das letras góticas a ilustrações que pontuam aspectos dos livros: perfeitos antecedentes da poesia concreta.

Como os livros de artista contemporâneos, também o livro medieval não estava preso ao literário. O livro iluminado, como as Bíblias e os Livros de Horas, diferem em muito dos "livros" literários daquela época, que circulavam pela oralidade e tinham poucas e precárias inscrições em pergaminhos de uso comum. A poesia trovadoresca e as novelas de cavalaria tinham na voz o seu principal suporte, sendo a canção a forma mais comum de propagação literária. Novelas como as de Cervantes, já no final da Idade Média, nos contam sobre o seu modo de acontecer, já que há um 
espaço privilegiado para a meta-reflexão literária em Dom Quixote, por exemplo.

Muitas vezes, os pergaminhos eram reutilizados, tornando a leitura difícil. Também a noção de autoria não tinha a função que lhe foi conferida posteriormente. Uma família, um dono de albergue, podia ter em casa um texto do qual desconhecia o conteúdo, já que eram poucos os que sabiam ler, e tinha de esperar um visitante educado para que as histórias fossem conhecidas. Uma vez ouvidas, elas eram passadas adiante em longas horas de serão comunitário. A presença física do livro apenas indicaria o rumo de um rito a ser repetido. Funcionam da mesma forma os livros mágicos, a Bíblia, o I Ching, o Pentateuco para a cabala, os livros de tarô e similares. No interessante ensaio Philobiblon, Ricardo de Bury, em 1345, contou a história dos livros sibilinos, cujo valor é inestimável. ${ }^{2}$ A palavra da oração tem também suas peculiaridades. Segundo Jakobson, a função mágica seria "a conversão de uma 'terceira pessoa' ausente ou inanimada em destinatário de uma mensagem conativa" (JAKOBSON, 2010, p.160). É também uma palavra interessada em efetuar uma alteração no mundo. Como outras palavras performativas, ela realiza uma ação: o "sim" dos casamentos, as palavras mágicas da feitiçaria, o juramento diante do juiz... Os livros de horas não contêm, portanto, um conteúdo metalinguístico ou poético no que se refere às funções de suas palavras.

É importante lembrar que a poesia trovadoresca e as novelas de cavalaria tinham na voz o seu principal suporte, sendo a canção a forma mais comum de propagação literária. A intermidialidade, analisada por Irina Rajewsky em interessante artigo $^{3}$, perpassa o desenvolvimento da literatura e reside em suas origens na voz do cantor.

Paul Zumthor, em A letra e a voz, demonstrou como a performance permeava essa literatura, da qual conhecemos apenas traços esmaecidos. Uma era que teve início no século XVII passa a valorizar a palavra escrita em detrimento da tradição oral, em um processo que tem nos atos jurídicos sua primeira marca: as leis passam a ser escritas e não proferidas por um rei. Esse desenraizamento passou a imperar de modo tão crucial que hoje é preciso fazer um certo exercício mental para entendermos que a literatura na Idade Média é uma fulguração de corpos que cantam: desde as canções das mal-casadas às canções de gesta e do amor cortês. Quanta diferença entre a "literatura" medieval e o livro de horas, livro como suporte do rito religioso, do desenho e da pintura.

Falar de Idade Média é também supor e fabular. As interpretações do período divergem entre historiadores e até mesmo entre os momentos da obra de cada um. É interessante comparar livros como A agonia da Idade Média de Jules Michelet e A Idade Média explicada aos meus filhos de Jacques Le Goff. O medievo é palco para a denúncia dos horrores da humanidade tanto quanto para a ilustração de um sonho infantil.

\footnotetext{
2 "Diz ele [Aulo Gélio] que uma velha que ninguém conhecia chegou-se a Tarquínio Soberbo, o sétimo rei romano, a quem ofereceu nove livros, os quais (como afirmou) continham oráculos divinos, mas que pediu por eles imensa fortuna, ao que o rei lhe disse que estava louca. Furiosa, ela atirou três dos livros ao fogo e pelos restantes exigiu a mesma quantia de antes. Negou ainda o rei, e novamente ela atirou três livros ao fogo e pediu a mesma soma. Por fim, de tal modo admirado, de boa vontade Tarquínio gastou por três livro a quantia com a qual poderia ter comprado nove. A velha logo desapareceu e não mais foi vista. Aqueles eram livros sibilinos, eu os romanos consultavam
}

como oráculo divino (...)". BURY, Ricardo de. Philobiblon, ou, O amigo do livro. Tradução do latim e notas de Marcelo Cid. Cotia, SP: Ateliê Editorial, 2007, pp. 36-7.

3 RAJEWSKY, Irina. "A fronteira em discussão: o status problemático das fronteiras midiáticas no debate contemporâneo sobre intermidialidade" (artigo) in.: intermidialidade e estudos interartes: desafiso da arte contemporânea / Thaïs Flroes Nogueira Diniz, André Soares Vieira, organizadores. - Belo Horizonte: Rona Editora: FALE/UFMG, 2012, pp. 51- 73. 
Na introdução ao livro de Michelet (1798-1874) aprendemos que ele teve dois distintos olhares sobre a época, os quais acompanharam os acontecimentos do século XIX. Se em um primeiro momento reinava o romantismo de uma visão idealizada do medievo como período de tranquila aspiração ao bem comum, na segunda parte (na qual consta o livro citado) Michelet vê a ldade Média como um momento monstruoso de desmandos da Igreja, opressão e trevas. É o aspecto agônico que se sobressai, pois ele vai desembocar em um Renascimento sempre seguro de si, e sem limites para o poder de um homem agora liberto da espiritualidade castradora. Todas essas nuances diversas apontam para a história como feitura de um discurso que funciona como espelho. Recuperar a Idade Média é sempre dizer quem somos.

Paul Zumthor aborda essa problemática em Falando de Idade Média. Nesse pequeno livro de reflexão metahistoriográfica fica evidente a necessidade do pesquisador de questionar as escolhas metodológicas assumidas, elencando as dificuldades concernentes ao objeto e ao contexto da pesquisa no século XX. Escreve Zumthor: "Não creio me equivocar quando digo, em 1979, que a Idade Média, do ponto de vista de nossas práticas sociais e de nossas ideologias, é mais atual do que era em 1879." Uma constatação que perpassa o livro é a de que a Idade Média nunca foi tão atual também porque ela traz inexoravelmente os questionamentos que perpassam a virada linguística, as filosofias da desconstrução, os fracionamentos metodológicos que marcaram o século passado.

A ausência de documentos e as muitas flutuações no decorrer da história a respeito dos valores conferidos a esse enorme período criam um ambiente de contrastes e deslocamentos constantes. Zumthor coloca a sua ênfase nos modos de sentir e agir com o corpo. O movimento geral vai de um corpo íntegro que contém em si saberes, poderes e atitudes para um corpo destituído dessas suas antigas funções, que vai sendo paulatinamente substituído pela escrita, reprimido pelos ritos, conjurado pela Igreja, sufocado pela razão.

Também esse movimento se dá na relação corpórea do livro através dos séculos: procurou-se fingir que ele não tinha materialidade, suprimindo suas forças. O mercado do livro, por mais paradoxal que possa parecer, suprimiu-lhe seu caráter de corpo, adequando-o a padrões de maior conforto para reprodução e relação de custo. A facilidade da multiplicação também gerou, pelas conveniências de mercado, o que Mallarmé dedura como a padronização danosa.

Père Salabert propõe dois conceitos que poderão guiar-nos nesta reflexão. Abordando uma pintura anêmica e uma pintura suculenta, ele mostra como essas duas manifestações artísticas lidam com a questão do corpo, sua presença física, seu apresentar da carne viva. A pintura medieval e renascentista seria anêmica, pois ali o corpo raramente aparece em sua visceralidade. As personagens não dão a conhecer suas entranhas, suas sinuosidades feitas de osso e pele. Já boa parte da pintura do século XX é suculenta, uma pintura que aborda justamente a carnalidade desse corpo que agora se mostra em seus pruridos, dobras, convulsões, em tudo o que ele tem de orgânico. Assim, poderíamos pensar que o livro da imprensa de larga escala (pocket, best seller, formatado em coleções) é anêmico; e o livro de artista contemporâneo suculento. Essa suculência é o que estou relacionando com o livro do Duc de Berry, ainda que a pintura que nele encontramos seja o melhor exemplo da pintura anêmica 
que Salabert teoriza. Em relação à estrutura livro, ele antecipa a materialização de uma suculência livresca que terá seu ápice no século XX.

Um movimento de aparecer e desaparecer se dá na relação corpórea do livro através dos séculos. Os artistas contemporâneos, a partir da riqueza recebida dessa longa tradição, trazem à tona a corporeidade do livro, investigando-a em várias frentes. Assim, o caráter de sequência espaço-temporal proposto por Carrión é levado a cabo em criações que podem suprimir o texto linguístico para se apoiar na fluidez da estrutura. O peso do corpo do livro, o espaço da página, seu caráter de sequência, têm então esplendor.

Durante séculos, procurou-se fingir que o livro não tinha materialidade, suprimindo suas forças. O mercado do livro, por mais paradoxal que possa parecer, suprimiu-lhe seu caráter de corpo, adequando-o a padrões de maior conforto para reprodução e relação de custo. A facilidade da multiplicação também gerou, pelas conveniências de mercado, o que Mallarmé dedurou como a padronização danosa.

Ainda em 1969, Marcel Broodhaers realizou o livro Un coup de dés jamais n'abolira le hazard. Apropriando-se do poema mallarmaico, o artista construiu uma sequência de páginas na qual os versos do poema aparecem tachados, consistindo em manchas pretas/cinzas sobre o fundo branco da página. O livro coloca em evidência algo que já estava na publicação de Mallarmé; porém um aspecto que pode ficar de escanteio durante uma leitura preocupada em desvendar os significantes. $O$ peso da disposição das fontes, tabulações, tamanhos, espaços vazios e relações visuais entre esses elementos vêm à tona em primeiro plano, apagando-se o significado das palavras para primazia do significante. Ulises Carrión apoiou-se nessa experiência.

Carrión, fundador da primeira loja de livros de artista, também cita os livros do brasileiro Wlademir Dias Pino como as mais belas realizações de poetas nesse gênero por ele apreciadas. Em 1956, Dias Pino criou A ave, livro feito de páginas transparentes, coloridas, perfuradas, tratadas manualmente a nanquim, cujo manuseio pelo leitor forma o poema, revelado apenas através do folhear. Considerado o primeiro livro-poema, ele inaugurou o gênero livros de artista na América Latina e influenciou os artistas neoconcretos bem como os poetas concretos em suas realizações em parceria com artistas, como os poemóbiles de Julio Plaza e Augusto de Campos. 


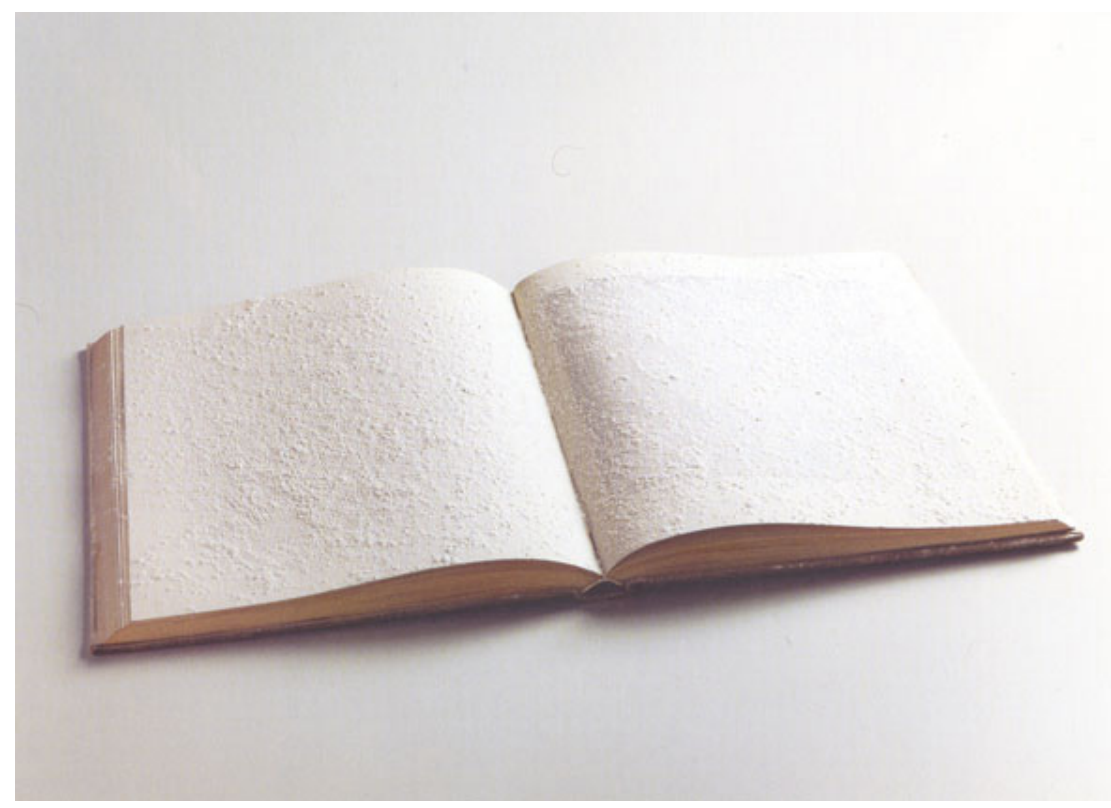

Matisse/Talco. Fonte da imagem: http://www.walterciocaldas.com.br/portu/comercio.asp?flg_Lingua=1\&flg_Tipo=D80\#, 30.04.2015.

Cito outros exemplos de trabalhos no gênero para mostrar como a forma livro obteve desenvolvimentos e experimentações que se direcionaram para a apreensão sinestésica do livro, afastando-se da legibilidade. Assim, Waltércio Caldas propôs, em 1978, Matisse/Talco, um livro no qual a ilustração de Matisse é completamente coberta por uma espessa camada de talco, gerando uma percepção que integra o não-ver ao olfato. A leitura/visualização se torna impossível, restando uma apreensão do livro voltada para a percepção sensorial de sua forma. Já o Livro de carne, de Artur Barrio (1979), tem como páginas pedaços sangrentos de carne, que podiam ser folheados na primeira versão. Também o poeta catalão Joan Brossa apresentou poemas-objeto cuja leitura não exige a decifração das letras do alfabeto e sim a leitura-percepção através dos sentidos do receptor. Torna-se assim interessante perceber como os poetas, ao construírem seus trabalhos, abandonaram o limite da língua para abarcar um horizonte de possibilidades mais amplo que, sem deixar de atingir seus fruidores, motivam-nos a exercitarem todos os seus sentidos para a mobilização do imaginário.

Gostaria ainda de sugerir que os livros de artista aqui abordados podem ser relacionados com as criações de poesia que tiveram lugar desde meados do século $X X$. Procedimentos comuns podem ser encontrados. Na poesia sonora, por exemplo, também abandona-se a primazia do significado para a composição de um objeto feito de puro significante a ser fruído livremente. Essas feituras não deixam de ser usos metalinguísticos da palavra, adequando-se aos conceitos de Jakobson sobre a função poética da linguagem. Elas apontam para a linguagem mesma, para suas possibilidades em termos de materialidade do significante. A ênfase recai sobretudo em uma visada meta-artística sobre os elementos perceptivos, sensoriais da fala, assim como a feitura dos livros de artista põe em primeiro plano os aspectos formais do livro. São convites a reflexões sobre a linguagem que nos instigam a perfazer o trajeto de sua história recôndita e reler o passado de forma crítica e renovada. 


\section{Arte-palavra que extrapola o livro}

Procurei pontuar tensões, encontros e desencontros entre palavra e imagem no livro medieval e no livro de artista, partindo de uma genealogia da poesia concreta. A palavra implicada nessa trajetória não é desprovida de um peso próprio e também de uma flexibilidade que a faz gerar tanto a visualidade da poesia concreta quanto $o$ requinte do livro medieval. É nas funções da palavra, seus modos de distensão e de utilização que reside a riqueza dessas proposições.

Para finalizar este percurso, chamo a atenção para uma criação que se dá na linguagem verbal e revela o caráter performativo dessa palavra poética que encontramos (mesmo quando não palavra) no livro medieval e no livro de artista. Trata-se de uma obra de Dario Robleto (1972) que integrou a 6a Bienal do Mercosul. No material pedagógico da mostra, encontramos algumas considerações reveladoras sobre o trabalho: "Em suas obras textuais, Robleto buscava um meio que lhe permitisse criar sem ter de usar dinheiro para produzi-las."

Apelando para a extrema anemia da materialidade, Robleto cria pequenos textos que seguem o formato de uma ficha de obra de museu. Informa o título da obra, os materiais necessários e em seguida dá uma pequena descrição de uma ação factível que poderíamos entender na clave do terrorismo poético: a subversão do cotidiano através da irrupção de deslocamentos imprevisíveis e impactantes. Ao final do pequeno texto normativo, em que a ação é descrita, está escrito "Dimensões variáveis" e o ano da obra, 1997.

Darei como exemplo a obra que consta no material pedagógico: Billie Canta o Blues e Tudo Importa. Segue o texto: Bússolas adquiridas em diversos lugares (bazares, briques, saldos de garagem, etc.) foram desmontadas e sob o polo sul de cada uma delas um minúsculo ímã foi instalado, fazendo com que o ponteiro ficasse sempre voltado para baixo. As bússolas foram, então, devolvidas aos lugares onde foram adquiridas.

A operação que Robleto promove é a de exibir, ao invés de obras, descrições textuais de obras, pequenos textos plotados e exibidos nas paredes. A diagramação é comum às fichas que geralmente encontramos nos museus, fontes limpas, texto perfeitamente legível e discreto. Há uma ausência em caso (a da obra que deveria acompanhar a ficha) e um procedimento de inversão: ao invés de estar na periferia, quase imperceptível, sem jamais concorrer com a pintura, o desenho, o vídeo ou a escultura; o texto é levado para o centro da parede, justamente onde deveria se encontrar a obra: ele é a obra.

Ao mesmo tempo, a obra que o texto descreve não se encontra ali: ela se dá na imaginação do leitor e em um espaço e tempo paralelos, onde pode transcorrer o ato. Trata-se de um uso performativo da palavra, pois o texto cria a ação que pode ter ocorrido ou pode ainda ocorrer em outro espaço e tempo.

Trago esse trabalho de Robleto como uma provocação sobre a relação entre palavra e imagem. Não é mais apenas materialidade do suporte em que ela se encontra (como o livro) que conta aqui, não é a carnadura visual das palavras que concorre para o jogo, pois esta é escondida por trás de um formato padrão (o da ficha de mu- 
seu) e de uma exibição quase sem atrativos de suculência. A materialidade do significante, em Robleto, procura assim se esconder por trás de um vazio e a obra se dá em um outro espaço, tão comum à literatura. Cria um universo outro, com os poderosos resultados de deslocamentos que geram rupturas no cotidiano.

Ainda assim, nessa desaparição há um engenho poderoso, que não é mais apenas o da visualidade: Robleto é artista porque compõe e exibe textos; como Mallarmé pensou-se poeta pois compunha mais do que textos, livros, sonhando com o Livro total.

A poesia, então, vai prescindir do livro; assim como o livro liberou-se da literatura. Se dos poetas modernos (do simbolismo mallarmaico) foi gerada a abertura para a poesia concreta, que desembocará no livro de artista (o próprio Carrión iniciou-se como poeta para depois abandonar a literatura); então agora é o artista que se liberta da obrigação de compor suculências visuais para optar pela palavra nua. 


\section{Referências}

BEARISTÓTELES, HORÁCIO, LONGINO. A poética clássica. Tradução de Jaime Bruna. São Paulo: Cultrix, 2005.

BARBOSA, Maria Aparecida. "Carl Einstein interdisciplinar: sobre Escultura negra (Negerplastik)". Pandemonium, São Paulo, n.18, Dez./2011, p.121-137. www.fflch. usp.brdllm/alemao/pandemoniumgermanicum.

BENJAMIN, Walter. Magia e técnica, arte e política: ensaios sobre literatura e história da cultura. Tradução de Sérgio Paulo Rouanet. São Paulo: Brasiliense, 1994.

BOURDIEU, Pierre. As Regras da Arte. Tradução Maria Lúcia Machado. São Paulo: Companhia das Letras, 2010, pp.152-159.

BRETON, André. L'amour fou. Paris: Éditions Gallimard, 1937. Nadja. Tradução de Ivo Barroso. São Paulo: Cosac Naify, 2007.

BROSSA, JOAN. Joan Brossa: desde Barcelona al Nuevo Mundo. (Catálogo) Institut Ramon Llull/Fundació Joan Brossa. Chile, Brasil, Argentina, Portugal, 2005/2006.

BURY, Ricardo de. Philobiblon, ou, O amigo do livro. Tradução do latim e notas de Marcelo Cid. Cotia, SP: Ateliê Editorial, 2007.

CAMPOS, Augusto de. Mallarmé. Augusto de Campos, Décio Pignatari, Haroldo de Campos. São Paulo: Perspectiva, 2010.

CAMPOS, Augusto de. PIGNATARI, Decio; CAMPOS, Haroldo de. Teoria da poesia concreta: textos críticos e manifestos 1950-1960. São Paulo: Ateliê, 2006.

CARRIÓN, Ulises. Book: Documentary material relating to the work of Ulises Carrión (1941-1989). Organizado e desenhado por James Langdon. Amsterdam: Eastside Projects, 2010.

ECO, Umberto. Arte e beleza na estética medieval. Trad. Mario Sabino. Rio de Janeiro: Record, 2010.

EINSTEIN, Carl. Negerplastik [Escultura Negra] Tradução de Fernando Scheibe e Inês de Araújo. Florianópolis: Editora da UFSC, 2011.

FONTIUS, Martin. "Imitação". In: COSTA LIMA, Luiz. Teoria da Literatura em suas fontes (volume 1). Rio de Janeiro: Civilizacão Brasileira, 2002, pp. 105-7.

GONÇALVES, Aguinaldo José, 1949. Laokoon revisitado: Relações homológicas entre texto e imagem. São Paulo: Editora da Universidade de São Paulo, 1994. 
. "A Estética Expressionista na Pintura e na Literatura". In: GUINBURG, J. Expressionismo. SP: Perspectiva, 2002, pp. 679-720.

ISER, Wolfgang. "Problemas da teoria da literatura atual: $O$ imaginário e os conceitos-chave da época". Tradução de Luiz Costa Lima. In.: COSTA LIMA, Luiz. Teoria da Literatura em suas fontes (volume 2). Rio de Janeiro: Civilizacão Brasileira, 2002, pp. 927-951.

JAKOBSON, Roman. Linguística e comunicação. Tradução de Isidoro Blikstein e José Paulo Paes. São Paulo: Cultrix, 2010.

LE GOFF, Jacques. A Idade Média explicada aos meus filhos. Trad. Hortencia Lencastre. Rio de Janeiro: Agir, 2007.

MALLARMÉ, Stéphane. Divagações. Trad. Fernando Scheibe. Florianópolis: Ed. da UFSC, 2010.

MENEZES, Philadelpho. A crise do passado: modernidade, vanguarda, metamodernidade. São Paulo: Experimento, 1994.

MICHELET, Jules. A agonia da Idade Média. Trad. Artemis Albuquerque Coelho, Plínio Augusto Coelho. São Paulo: EDUC, Imaginário 1992.

POUND, Ezra. ABC da literatura. [Trad. Augusto de Campos e José Paulo Paes] São Paulo: Cultrix, s/d.

RAJEWSKY, Irina. "A fronteira em discussão: o status problemático das fronteiras midiáticas no debate contemporâneo sobre intermidialidade" (artigo). In.: Intermidialidade e estudos interartes: desafios da arte contemporânea / Thaïs Flroes Nogueira Diniz, André Soares Vieira, organizadores. - Belo Horizonte: Rona Editora: FALE/ UFMG, 2012.

SALABERT, Pere. La redención de la carne. Barcelona: CENDEAC, 2004.

SILVEIRA, Paulo. A página violada: da ternura à injúria na construção do livro de artista. Porto Alegre: Editora da UFRGS, 2008.

SOUSA, Márcia Regina Pereira de. O livro de artista como lugar tátil. Florianópolis: Editora da UDESC, 2011.

ZUMTHOR, Paul. A letra e a voz: A “literatura” medieval. Trad. Amálio Pinheiro, Jerusa Pires Ferreira. São Paulo: Companhia das Letras, 1993. 